\title{
TO ASSESS THE NUTRITIONAL STATUS OF CHILDREN IN RELATION TO TIME OF ONSET OF BREAST FEEDING AND WEANING AMONG ZERO TO TWO YEARS.
}

Boramma G, S. R. Nigudgi, Rajashekar Kapatae, Srinivas Reddy.

1. Professor, Department Of Community Medicine, M.R Medical College Gulbarga.

2. Professor, Department Of Community Medicine, M.R Medical College Gulbarga.

3. Professor H.O.D, Department Of Community Medicine, M.R Medical College Gulbarga.

4. Statistician, Department Of Community Medicine, M.R Medical College Gulbarga.

\section{CORRESPONDING AUTHOR:}

Dr. Boramma G.

H.No 2-907/25A.gubbi Colony,

Sedam Road, Gulbarga.

E-mail:borammak504@gmail.com

\begin{abstract}
INTRODUCTION:-Nutritional status of vulnerable groups like under 5 children, expectant and lactating mothers is the indicator of health status of the nation. In children nutrition and infection are important factors that affect growth of children. AIMS AND OBJECTIVES:-To assess the nutritional status of children in relation to time of onset of breast feeding and weaning among zero to two years. MATERIAL AND METHODS:-A cross sectional study was conducted in a peri-urban area of Gulbarga including all the 172 children between the age group of zero to two years. Information was collected by using pre-tested proforma. The weight of child was taken directly by using platform type of (spring balance) weighing machine. Grading of malnutrition was done using Gomez Classification, by plotting on a standard WHO growth chart to find the grade of malnutrition according to weight for age. RESULTS:-Out of 172 children, 91 (52.91\%) were having normal nutrition status followed by 35(20.35\%), 35(20.35\%), $9(5.23 \%)$ and 2 (1.16\%) were having grade I, II, III, and IV type of malnutrition respectively.28 mothers breast fed their child immediately $20(71.43 \%)$ had normal nutritional status and $8(28.57 \%)$ were below normal nutritional status, whereas mothers who breast fed their child after 24 hours only 6(13.95\%) children showed normal nutritional status and 37(86.05\%) children were below normal nutritional status. It was observed that out of 172 children were weaning was initiated after 1 year in 47 children, out of which 19 (40.43\%) showed normal nutritional status and 28 (59.57\%) showed below normal nutritional status. CONCLUSION:-exclusive breastfeeding to be done till 6 months. The relation between time of onset of breastfeeding was statistically significant. Nutritional status was normal in maximum number of children where the weaning was started between 6 months to 1year which clearly attributes to exclusive breastfeeding done by mothers to their infants.
\end{abstract}

KEY WORDS:-Breastfeeding, weaning, malnutrition.

INTRODUCTION: Nutritional status of vulnerable groups like under 5 children, expectant and lactating mothers is the indicator of health status of the nation. In children nutrition and infection are important factors that affect growth of children. Malnutrition especially strike those who lack 
nutritionally adequate diet, not protected from frequent illnesses and do not receive adequate care. ${ }^{1}$ Breastfeeding remains the simplest, healthiest and least expensive feeding methods that fulfil the infants need. ${ }^{2}$ Breastfeeding lowers mortality associated with bloody and chronic diarrhoea and confers apparent protection at least upto 3 months after weaning. ${ }^{3}$ Timely optimal feeding, complimentary feeding practices are also an important factor contributing to the proper growth of infants. This period is usually associated with the number of concerns and problems in developing countries like what food should be given to the child, how and when they should be given. ${ }^{4}$ In the developing countries the age of introduction of weaning foods is of public health importance because of risk of diseases particularly diarrheal diseases from contaminated weaning food and the risk of growth faltering and malnutrition from delayed weaning. ${ }^{5}$ Childhood malnutrition in poor households has been well documented in India, with the highest rates observed in those aged 12-23 months. Country wide National Family Health Survey II (NFHSII) data show mean underweight prevalence increases from $11.9 \%$ among infants fewer than six months of age to $58.4 \%$ at $12-23$ months of age. ${ }^{6}$ The objective of this study is to evaluate the relation of time of onset of breastfeeding and weaning among 0-2 years of children and their nutritional status. The results of the study will add to the existing knowledge of breastfeeding and appropriate weaning practices in our community.

AIMS AND OBJECTIVES: - To assess the nutritional status of children in relation to time of onset of breast feeding and weaning among zero to two years.

MATERIAL AND METHODS :- A cross sectional study was conducted in Rajapur, a peri-urban area of Gulbarga also a field practice area of department of community medicine, M R Medical College, Gulbarga including all the 172 children between the age group of zero to two years.

Information was collected by using pre-tested proforma. The weight of child was taken directly by using platform type of (spring balance) weighing machine.

Grading of malnutrition was done using Gomez Classification, by plotting on a standard WHO growth chart to find the grade of malnutrition according to weight for age.

Data was entered and tabulated in Microsoft Excel. Percentages and Chi-square test were used wherever relevant.

RESULTS AND DISCUSSION: Out of 172 children, 91 (52.91\%) were having normal nutrition status followed by 35 (20.35\%), 35 (20.35\%), 9 (5.23\%) and 2 (1.16\%) were having grade I, II, III, and IV type of malnutrition respectively (Table 1). 28 mothers who breastfed their child immediately,20(71.43\%) had normal nutritional status and $8(28.57 \%)$ were below normal nutritional status, whereas mothers who breast fed their child after 24 hours, only 6(13.95\%) children showed normal nutritional status and 37(86.05\%) children were below normal nutritional status. It clearly indicates that as the onset of breast feeding time delays the nutritional status of child who showed below normal nutritional status increases ie, 37 (86.05\%).The relation between nutritional status and time of onset of breast feeding was statistically significant (table 2). In similar study done by Rasania SK et al7 in 72(20.3\%) children where breast-feeding was initiated within two hours of birth while in 56(15.82\%) children it was delayed beyond two days of delivery. These were the children in whom severe degree of malnutrition was observed $(\mathrm{p}<0.001)$. Similar 
observations was made by B.B.Khare in Assam that in $44.72 \%$ children breast feeding was started within 6 hours and in 15.5\% children breast feeding was started between 7 to 24 hours and in $40.3 \%$ of the children breast feeding was started after 24 hours. ${ }^{8}$ Chandramadhuri et.al in his study noticed that $7 \%$ of the mother's initiated breast feeding within 1 hour,22\% within 2-6 hours, 30\% on $2^{\text {nd }}$ day, $28 \%$ on $3^{\text {rd }}$ day, $3 \%$ on $4^{\text {th }}$ day and $3 \%$ on $5^{\text {th }}$ day and $4 \%$ on $6^{\text {th }}$ day. .9

It was observed that out of 172 children weaning was initiated after 1 year in 47 children, out of which 19 (40.43\%) showed normal nutritional status and 28 (59.57\%) showed below normal nutritional status. In 51 children who have started weaning before 6 months out of them 28(54.90\%) showed below normal nutritional status, whereas who have started weaning at 6 months to 1 year out of 74 children only 25(33.78\%) showed below normal nutritional status. Hence the incidences of below normal children are more in those children where the weaning was started before six months and after one year (table 3). In similar study done by Umar et al ${ }^{10}$ showed that out of the 143 study subjects, only 32 (22.3\%) commenced weaning before the age of 4months, 65 (45.5\%) between 4-6 months with only 28 (19.6\%) practicing weaning at 6 months.Similar study done by B.B Khare.et.al ${ }^{8}$ in Assam, observed that weaning was initiated within 1-3 months by $21.2 \%$ of mother's, between $4-9$ months by $38.1 \%$ mother's between $7-12$ months by $21.8 \%$ mother's above 12 months by $18.9 \%$ mother's. The reason for maximum children having normal nutritional status in whom weaning was started at 6 months- 1 year can be attributed to exclusive breast feeding done by mothers to their infants.

CONCLUSION: From our study we conclude that the exclusive breastfeeding to be done till 6 months. The relation between times of onset of breastfeeding was statistically significant. Nutritional status was normal in maximum number of children where the weaning was started between 6 months to 1year which clearly attributes to exclusive breastfeeding done by mothers to their infants.

\section{REFERENCES:-}

1. UNICEF Child malnutrition statistics and monitoring 2012

2. Kramer MS, Kakuna R. the optimal duration of exclusive breast feeding, a systematic review, WHO, Geneva, Switzerland. 2002. WWHO/NHO/01.08

3. Andre Briens, Bogan Wojtyniak, Michael G M Rowland, Breastfeeding, nutritional state and child survival in rural Bangladesh. British medical journal 1988; 296, 879-882.

4. Hazel S.CeyhunG,Tanzer F, Sanli C. traditional beliefs as forgotten influencing factors on breastfeeding performance in turkey. Saudi Medical Journal 2006; 27(4) 511-518.

5. Uwaegbute AC .weaning factors and weaning foods of the Hausas, Yorubas and Ibos of Nigeria. Ecology of Food and nutrition 1990; 26; 139-153.

6. Yasmeen Khan, Nelofer Khan, nutritional status of children (0-24 months) in Jammu \& Kashmir and Ladakh region. International Journal of Scientific and Research Publications, June 2012; 6(2) ; 1-7.

7. Rasania SK, Sachdev TR, Nutritional Status and Feeding Practices of Children Attending MCH Centre. Indian Journal of Community Medicine. 2001 Vol. 26, No. 3 (2001-07 - 200109) 
8. Khare BB et al, "Feeding and Weaning practices during infancy and early childhood period in India”, IJPSM (1993), Vol.24,No.4,p.127.

9. Chandramadhuri, Shashi k, "Breast feeding practices- The obstetrician role", The Journal of Obstetrics \& Gynaecology of India (1999), p.69.

10. A. S. Umar and M. O. Oche, Breastfeeding and Weaning Practices in an Urban Slum, North Western Nigeria. International Journal of TROPICAL DISEASE \&Health ;3(2): 114-125, 2013

Table 1: Distribution of children according to degree of malnutrition

\begin{tabular}{|c|c|c|}
\hline Degree of malnutrition & Number & Percent. \\
\hline Normal & 91 & 52.91 \\
\hline First degree & 35 & 20.35 \\
\hline Second degree & 35 & 20.35 \\
\hline Third degree & 9 & 5.23 \\
\hline Fourth degree & 2 & 1.16 \\
\hline Total & 172 & 100 \\
\hline
\end{tabular}

Table 2: Relation between time of onset of breast feeding and nutritional status of child.

\begin{tabular}{|c|c|c|c|c|c|c|c|c|}
\hline \multirow{3}{*}{ Breast feeding } & \multicolumn{4}{|c|}{ Nutritional status of child } & \multirow{2}{*}{\multicolumn{2}{|c|}{ Total }} & \multirow{3}{*}{ Chi Square } & \multirow{3}{*}{$\mathrm{p}$ value } \\
\hline & \multicolumn{2}{|c|}{ Normal } & \multicolumn{2}{|c|}{ Below Normal } & & & & \\
\hline & No & $\%$ & No & $\%$ & No & $\%$ & & \\
\hline Immediate & 20 & 71.43 & 8 & 28.57 & 28 & 100.00 & & \\
\hline $1 / 2$ to 1 hour & 32 & 66.67 & 16 & 33.33 & 48 & 100.00 & & \\
\hline 1 to 6 hour & 18 & 72.00 & 7 & 28.00 & 25 & 100.00 & & \\
\hline 6 to 12 hours & 3 & 33.33 & 6 & 66.67 & 9 & 100.00 & $=39.54$ & $<0.001$ \\
\hline 12 to 24 hours & 12 & 63.16 & 7 & 36.84 & 19 & 100.00 & & \\
\hline$>24$ hours & 6 & 13.95 & 37 & 86.05 & 43 & 100.00 & & \\
\hline Total & 91 & & 81 & & 172 & & & \\
\hline
\end{tabular}

Table 3: Relation between time of onset of weaning and nutritional status of child

\begin{tabular}{|c|c|c|c|c|c|c|c|c|}
\hline \multirow{2}{*}{ Weaning } & \multicolumn{2}{|c|}{ Normal } & \multicolumn{2}{|c|}{ Below normal } & \multicolumn{2}{c|}{ Total } & \multirow{2}{*}{$\begin{array}{c}\text { Chi } \\
\text { Square }\end{array}$} & \multirow{2}{*}{$\mathrm{p}$ value } \\
\cline { 2 - 7 } & No & $\%$ & No & $\%$ & No & $\%$ & & \\
\hline$<6 \mathrm{~m}$ & 23 & 45.10 & 28 & 54.90 & 51 & 100 & & \\
\hline $6 \mathrm{~m}-1 \mathrm{y}$ & 49 & 66.22 & 25 & 33.78 & 74 & 100 & \multirow{3}{*}{0.448} & \multirow{2}{*}{0.009} \\
\hline$>1 \mathrm{y}$ & 19 & 40.43 & 28 & 59.57 & 47 & 100 & & \\
\hline & 91 & 52.91 & 81 & 47.09 & 172 & 100 & & \\
\hline
\end{tabular}

